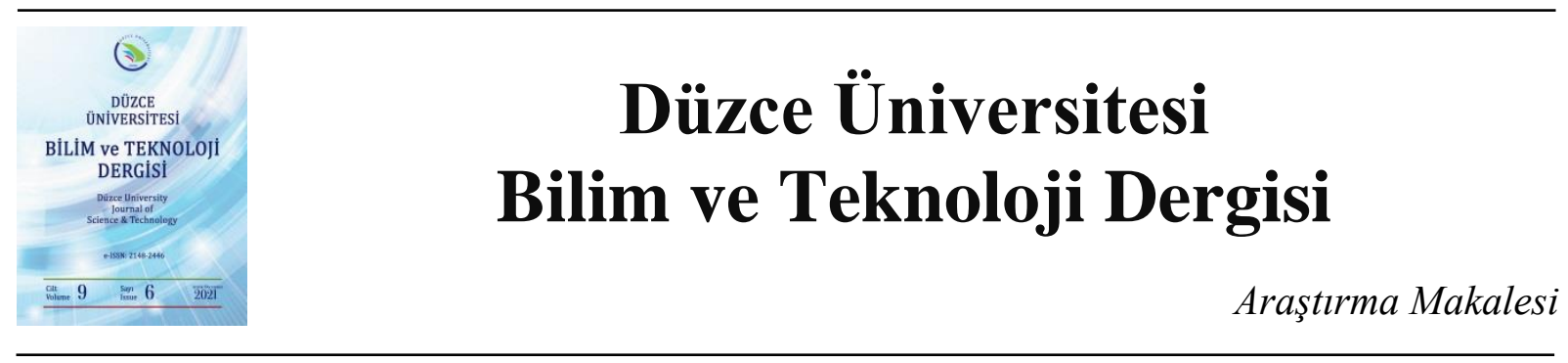

\title{
Bulanık Mantık Tabanlı Performans Değerlendirme Algoritmasının Tasarımı ve Uygulamas $1^{1}$
}

\author{
Hamit ARMAĞAN \\ Enformatik Bölümü, Rektörlük, Süleyman Demirel Üniversitesi, Isparta, TÜRKIYYE \\ Sorumlu yazartn e-posta adresi: hamitarmagan@sdu.edu.tr \\ DOI:10.29130/dubited.1015317
}

\begin{abstract}
$\underline{\mathrm{OZZ}}$
Günümüzde eğitim ve iletişim teknolojilerinin gelişmesiyle birlikte bu teknolojiler eğitim alanında yaygın olarak kullanılmaktadır. Özellikle yükseköğretimde bu teknolojiler sayesinde uzaktan eğitim, karma eğitim gibi modeller hızla çoğalmaktadır. Uzaktan eğitim modeli yüz yüze eğitim modeline göre avantajları olduğu gibi dezavantajları da bulunmaktadır. Uzaktan eğitimin yapıldığı ortamın yeterli düzeyde teknolojik donanıma sahip olması, ses akustiği, aydınlatma şiddeti gibi temel bileşenlerin uygun aralıkta olması öğrencilerin uzaktan eğitime bakış açısını olumlu etkilemektedir. Bu çalışmada uzaktan eğitim sistemleri için öğrenci memnuniyet performansı değerlendirme parametrelerine (ses kalitesi, görüntü kalitesi, eğitim teknolojileri) bağlı olarak hesaplamak için bulanık mantık tabanlı bir model tasarlanmıştır. Süleyman Demirel Üniversitesi Uzaktan Eğitim Meslek Yüksek Okulu bilgisayar programcılığı ikinci sınıf öğrencilerinin katılımı ile uzaktan eğitim sistemi için öğrenci memnuniyeti performans değerlendirme çalışması yapılmıştır. Bu çalışmadan elde edilen veriler geliştirilen bulanık küme tabanlı değerlendirme algoritması ile uzaktan eğitim sistemi için öğrenci memnuniyeti performans değerleri hesaplanmıştır. Çalışmanın ikinci aşamasında; hesaplanan performans değeri ile öğrencilerin genel not ortalama eşleştirilmiştir. Elde edilen veri setinde korelasyon, eğri uydurma, merkezi eğilim ölçüleri ve merkezi dağılım ölçüleri analizi için gerekli hesaplamalar yapılmıştır. Çalışmanın sonuç aşamasında elde edilen tüm veriler bir bütün olarak değerlendirmeye alınmıştır. Parametreye bağlı olarak uzaktan eğitim sistemi için öğrenci memnuniyet performansının öğrenci başarısı üzerine etkisi istatiksel yöntemlerle karşılaştırma yapılarak sonuç bölümünde paylaşılmıştır.
\end{abstract}

Anahtar Kelimeler: Bulanık mantık, Matematiksel modelleme, Ĕ̆ri uydurma, Tanımlayıcı istatistik

\section{Design and Application of Fuzzy Set Based Assessment Algorithm}

\begin{abstract}
Today, with the development of education and communication technologies, these technologies are widely used in the field of education. Especially in higher education, models such as distance education and coeducation are increasing rapidly thanks to these technologies. The distance education model has both advantages and disadvantages compared to the face-to-face education model. The fact that the environment in which distance education takes place has sufficient technological equipment, the basic components such as sound acoustics and lighting intensity are in the appropriate range, positively affect the students' perspective on distance education. In this study, a fuzzy logic-based model was designed to calculate student satisfaction performance based on evaluation parameters (sound quality, image quality, educational technologies) for distance education systems. With the participation of Süleyman Demirel University Distance Education Vocational School second year computer programming students, a student satisfaction performance evaluation study was conducted for the distance education system. The student satisfaction performance values for the distance education system were calculated with the fuzzy set-based evaluation algorithm developed from the data obtained from this study. In the second stage of the study; The calculated performance value was matched with the overall grade point average of the students. Necessary calculations were made for the analysis of correlation, curve fitting, measures of central tendency and measures of central distribution in the obtained data set. All data obtained at the conclusion stage
\end{abstract}

${ }^{1}$ ICAIAME 2021 konferansında sunulmuş ve özet olarak yayınlanmıştır.

Geliş: 27/10/2021, Düzeltme: 10/12/2021, Kabul: 14/12/2021 
of the study were evaluated as a whole. Depending on the parameter, the effect of student satisfaction performance on student success for the distance education system was compared with statistical methods and shared in the conclusion section.

Keywords: Fuzzy logic, Mathematical modeling, Curve fitting, Descriptive statistics

\section{GİRIS}

Günümüzde uzaktan eğitim alanında akıllı sınıf, e-sınıf ve e-stüdyo gibi uzaktan eğitim ortamları online eğitim veren üniversitelerde ve kurumlarda ders alan öğrencilerin derse aktif katılımlarını ve öğretim elemanlarının interaktif dersler oluşturmalarını sağlamak amacıyla etkin bir şekilde kullanılmaktadır. Bunlardan "e-stüdyo" modeli eğitim teknolojilerinin bilişim ergonomisine uygun olarak kullanıldığı ses, görüntü, aydınlatma gibi temel parametreleri optimize edilmiş uzaktan eğitimin kolay ve interaktif bir şekilde yapılmasını sağlamak amacıyla tasarlanmış ve geliştirilmiş bir modeldir. Süleyman Demirel Üniversitesi Uzaktan Eğitim Meslek Yüksek Okulunda tüm bölümlerin dersleri bu platform üzerinden gerçekleştirilmektedir.

Aşağıda şekil 1 de e-stüdyo içerisindeki donanımlar gösterilmiştir. Verilen numaralara göre donanımlar sırasıyla interaktif ekran, interaktif akıllı tahta, kısa atım projeksiyon, ses mikseri, mikrofon ve ptz kamera şeklindedir. Bu donanımlar sayesinde bilgisayar ortamındaki her türlü belge ve görüntü üzerinde yazma ve çizme işlemleri kolayca yapılabilmektedir. Bu sayede dersler etkileşimli olarak yapılabilmektedir. Kullanılan senkron eğitim platformu yazılımları ile ögrencilerin bu dersleri sesli ve görüntülü olarak izlemeleri sağlanmaktadır. Bu özelliklere ek olarak senkron eğitim platformu yazılımları sayesinde dersler video formatında kayıt edilmekte ve arşivlere internet üzerinden erişim yapılabilmektedir. E-Stüdyo ortamında kullanılan PTZ(pan,tilt,zoom) kamera sayesinde öğretim elemanının dersi anlatacağı farklı noktalar kameraya kayıt edilmekte ve ders sırasında kontrol ünitesi üzerinden kameranın öğretim elemanına odaklanması sağlanmaktadır. Senkron eğitim platformu yazılımları ile canlı derslerde öğretim elemanına öğrenciler sesli yada yazılı olarak soru sorabilmektedir. Sesli sorularda karşılaşılan sesin geri dönmesi, yankı, vb. olumsuz durumlar kullanılan "USB Audio Interface" donanımı ve e-stüdyo içerisindeki ses akustik ve yalıtımı sayesinde problemsiz olarak sağlanmaktadır.
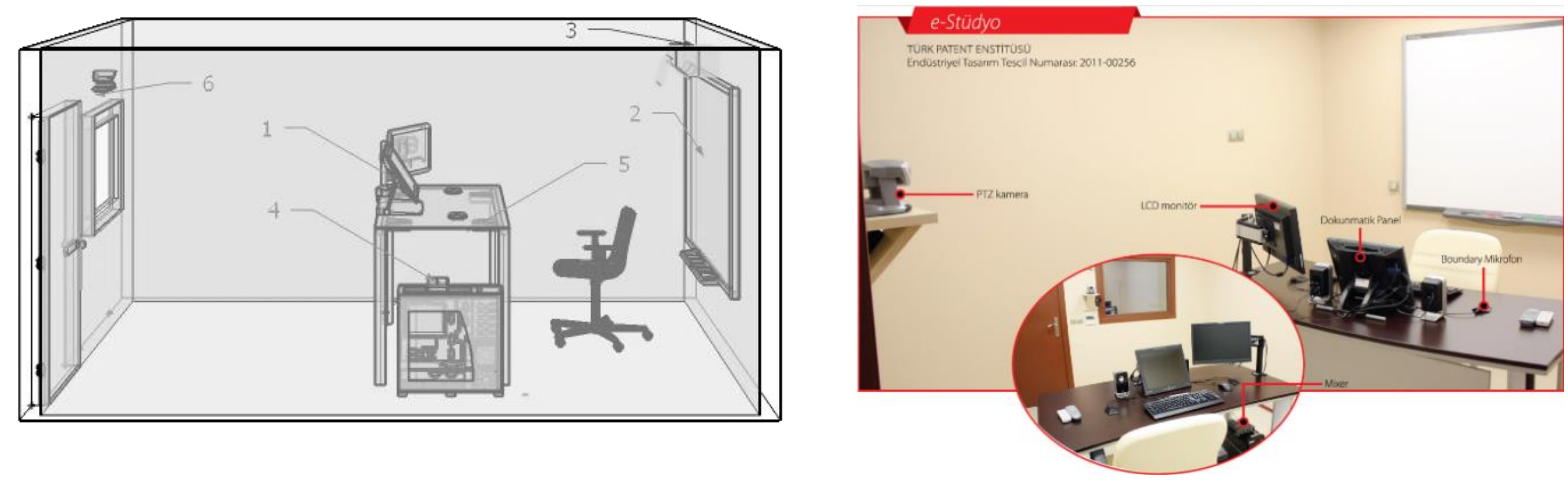

Şekil 1.e-Stüdyo tasarım modeli ve yan görünüm

Ayrıca e-stüdyo içerisinde yaptığımız aydınlatma analizi ve iyileştirmeleri ile görüntü kalitesinin en uygun aralıkta olmasını sağlamıştır. Aydınlatma seviyesinin uygun aralıklara getirilmesi ile ortamda çalışan donanımların da performansının artması sağlanmıştır. Kameranın renk derinliğinin artması yani görüntüdeki renklerin gerçeğe yaklaşması, interaktif tahta üzerindeki projeksiyon ışığının ortam aydınlatma seviyesi ile azaltılmaması sonucunda interaktif tahta üzerindeki renk kontrastının korunması, ortamda yansıma, parlama, titreşim seviyeleri kontrol edilerek öğretim elemanının göz 
sağlığının korunması, konsantrasyon ve verimliliğin artırılması sağlanmıştır. Bununla da yaptığımız online derslerin yada oluşturduğumuz arşiv kayıtlarının kalitesinin artırılması sağlanmıştır.

Akıllı sınıf, e-sınıf, e-stüdyo gibi uzaktan eğitim ortamları ile ilgili literatürde birçok çalışma bulunmaktadır. Bu çalışmalarda eğitim teknolojisi, bilişim ergonomisi, bu eğitim ortamlarında öğrencilerin tutum ve davranışları hakkında araştırmalar yapılmıştır. Shi [1], akıllı sınıfı; gerçek bir sınıf deneyimine benzer bir uzaktan eğitim deneyimi sağlamak için ses tanıma, bilgisayarla görme ve diğer teknolojileri birleştirir şeklinde tanımlamıştır. Winer [2], öğrenciler için akıllı sınıftaki çoklu sunum teknikleri ve ders kayıtlarına sonradan erişim sağlamalarını eğitim açısından bir firsat olduğunu ifade etmiştir. Shi [3], uzaktan eğitim sisteminde kullanılan akıllı sınıfları, öğretmenler için insanbilgisayar etkileşimini üst seviyeye çıkaracak sistem olarak tanımlamaktadır. Ren ve Xu [4], akı1lı sınıfların, elektronik ortamlarla kullanıcıları bütünleştiren yeni bir eğitim ortamı olduğunu ifade etmiştir. Wang [5], akıllı sınıf ortamlarını yalnızca eğitim ortamlarında değil, her türlü toplantı ve uygulamaları için de kullanılabileceğini belirtmiştir. Carter ve Linder [6], akıllı sınıflar ve işbirlikçi öğrenme arasında ilişki olduğunu vurgulamışlardır. Tiburcio ve Finch [7], akıllı sınıfların öğrencilerin etkileşimli davranışlarını olumlu yönde etkilediğini belirtmişlerdir. Yau [8], akıllı sınıfın üniversite öğrencileri arasında işbirliğine dayalı öğrenmeyi kolaylaştırdığını ifade etmiştir. Bautista ve Borges [9], akıllı bir sınıfın kullanıcıların ihtiyaçlarına göre uyarlanmış, rahat, kişiselleştirilmiş, güvenli ve teknolojik olması gerektiğini belirtmişlerdir. Ren ve Xu [10], akıllı sınıfta öğretmenin hareketlerini algılayan hareket tanıma sisteminin etkileşim üzerine olumlu katkılarını belirtmişlerdir.

$\mathrm{Bu}$ çalışmada uzaktan eğitim sistem değerlendirme parametrelerine bağlı olarak uzaktan eğitim sistemleri için öğrenci memnuniyet performansını değerlendirmek amacıyla bulanık mantık tabanlı bir model tasarlanmıştır

Bulanık mantık, 1965 yılında L. Zadeh'in "Fuzzy Sets" başlığı ile yayımladığg bir makalenin [13,14] sonucu ortaya çıkmış bir mantık yapısıdır. Bulanık mantığın temeli bulanık küme kavramına dayanmaktadır [13-15]. Bulanık küme, klasik kümenin bir genellemesidir. Klasik küme yaklaşımında bir varlık bir kümenin ya elemanıdır, ya da değildir. Dolayısıyla bir $A$ klasik kümesinin karakteristik fonksiyonu olan $X_{A}: E \rightarrow\{0,1\}$, varlık-kümeye üyelik ilişkisi bakımından sadece 0 yada 1 değerlerini alır. Bulanık küme yaklaşımında ise her bir varlığın kümeye bir aidiyet (üyelik) derecesi vardır. Varlıkların üyelik derecesi, [0,1] kapalı aralığında herhangi bir değer alabilir[11-15]. Bir A bulanık kümesini temsil eden karakteristik fonksiyona bu kümenin üyelik fonksiyonu denir ve genellikle $\mu_{A}: E \rightarrow[0,1]$ ile gösterilir [13-15].

$E$ bir evrensel küme ve $A \subset E$ bir klasik küme olmak üzere $A$ nın karakteristik fonksiyon gösterimi olan, $X_{A}: E \rightarrow\{0,1\}$ bulanık kümelerde yerini üyelik fonksiyonuna bırakır. $\mathrm{Bu}$ da; $\mu_{A}: E \rightarrow[0,1]$ şeklinde gösterilir. İkinci gösterimde $A$ bir bulanık kümedir [11-15].

Performans değerlendirmesi genellikle değerlendirmesi yapılacak sistemin parametrelerinin sayısal notlar verilerek veya sözlü ifadeler kullanılarak derecelendirilmesidir. Bu notlar ve sözel ifadeler aritmetik veya istatistiksel yöntemler yardımıyla sistemin başarısını ifade etmek için kullanılır. Farklı değerlendirme bileşenlerinin bir kombinasyonu genellikle notların farklı paylaştırılması ile kullanılmaktadır. Aritmetik yöntemlerin kullanımında örneğin; her bir değerlendirmeden gelen farklı puanlar tek bir puan elde etmek için toplanabilir. Değişik değerlendirmelerden elde edilen puanların ortalamasının hesaplanması gibi basit istatistiksel yöntemler de sık kullanılmaktadır. Performans değerlendirmeleri tanımlayıcı istatistik yöntemlerinden merkezi eğilim ölçüleri ya da merkezi dağılım ölçüleri kullanılarak da yapılabilir.

$\mathrm{Bu}$ çalışmanın amacı, performans değerlendirmelerinde istatistiksel değerlendirme yöntemlerinden farklı olarak, bulanık kümeleri kullanan araçları incelemektir. Örneğin bir sistemin performans durumu değerlendirilirken "kötü", "orta" , "iyi”" gibi, derecesi ve niteliği sistemi değerlendiren kişiye veya bulunduğu ortamın kendine özgü koşullarına göre farklılıklar gösteren birtakım sözel ifadeler kullanılır. Bu tip belirsizlikler matematiksel olarak bulanık mantık yardımıyla modellenebilir $[11,12]$. 


\section{MATERYAL VE METOT}

\section{A. MATERYAL}

Çalışmamızda uzaktan eğitim sistemi için öğrenci memnuniyet performansını değerlendirmek amacıyla anket çalışması yapılmıştır. Anket Süleyman Demirel Üniversitesi, Mühendislik Fakültesi, Karma (Uzaktan) Eğitim Bilgisayar Mühendisliği öğrencileri ile Süleyman Demirel Üniversitesi, Uzaktan Eğitim Meslek Yüksek Okulu, Bilgisayar programcılığı öğrencilerine uygulanmıştır. Anket mühendislik öğrencilerine yüz yüze çoktan seçmeli olarak uygulanmış, bilgisayar programcıllı̆̆ öğrencilerine ise online olarak sunulmuştur. Anketle ilgili bilgiler aşağıda tablo1 de verilmiştir. SDÜ, Uzaktan Eğitim Meslek Yüksek Okulu, Bilgisayar Programcıllğı öğrencilerimizin anketleri eğitim yönetim sistemi üzerinden online olarak yapılmıştır.

Tablo 1. Bulanık küme tabanlı değerlendirme algoritmasının giriş parametreleri (uzaktan eğitim sistemi için ögrenci memnuniyet performans anketi)

\begin{tabular}{|c|c|c|c|c|}
\hline Soru & Seçenekler & Uygulanan Bölüm & $\begin{array}{l}\text { Uygulama } \\
\text { Şekli }\end{array}$ & Sayı \\
\hline \multirow{2}{*}{$\begin{array}{l}\text { Canlı derslerde ve arşiv } \\
\text { kayıtlarında ses } \\
\text { kalitesini yeterli } \\
\text { buluyor musunuz? }\end{array}$} & \multirow{2}{*}{$\begin{array}{l}\text { Çok İyi } \\
\text { İyi } \\
\text { Orta } \\
\text { Kötü } \\
\text { Çok Kötü } \\
\text { Fikrim } \\
\text { Yok }\end{array}$} & $\begin{array}{l}\text { SDÜ, Mühendislik Fakültesi, } \\
\text { Karma (Uzaktan) Eğitim } \\
\text { Bilgisayar Mühendisliği }\end{array}$ & $\begin{array}{l}\text { Yüz yüze } \\
\text { Çoktan seçmeli }\end{array}$ & 50 \\
\hline & & $\begin{array}{l}\text { SDÜ, Uzaktan Eğitim Meslek } \\
\text { Yüksek Okulu, Bilgisayar } \\
\text { Programc1lığ } 1\end{array}$ & $\begin{array}{l}\text { Online } \\
\text { Çoktan Seçmeli }\end{array}$ & 68 \\
\hline \multirow{2}{*}{$\begin{array}{l}\text { Canlı derslerde ve arşiv } \\
\text { kayıtlarında ekran } \\
\text { paylaşımı ve web } \\
\text { kamera görüntü } \\
\text { kalitesini yeterli } \\
\text { buluyor musunuz? }\end{array}$} & \multirow{2}{*}{$\begin{array}{l}\text { Çok İyi } \\
\text { İyi } \\
\text { Orta } \\
\text { Kötü } \\
\text { Çok Kötü } \\
\text { Fikrim } \\
\text { Yok }\end{array}$} & $\begin{array}{l}\text { SDÜ, Mühendislik Fakültesi, } \\
\text { Karma (Uzaktan) Eğitim } \\
\text { Bilgisayar Mühendisliği }\end{array}$ & $\begin{array}{l}\text { Yüz yüze } \\
\text { Çoktan seçmeli }\end{array}$ & 50 \\
\hline & & $\begin{array}{l}\text { SDÜ, Uzaktan Eğitim Meslek } \\
\text { Yüksek Okulu, Bilgisayar } \\
\text { Programcilığ } 1\end{array}$ & $\begin{array}{l}\text { Online } \\
\text { Çoktan Seçmeli }\end{array}$ & 68 \\
\hline \multirow{2}{*}{$\begin{array}{l}\text { Canlı derslerde } \\
\text { İnteraktif eğitim için } \\
\text { Eğitim teknolojilerini } \\
\text { yeterli buluyor } \\
\text { musunuz? }\end{array}$} & \multirow{2}{*}{$\begin{array}{l}\text { Çok İyi } \\
\text { İyi } \\
\text { Orta } \\
\text { Kötü } \\
\text { Çok Kötü } \\
\text { Fikrim } \\
\text { Yok }\end{array}$} & $\begin{array}{l}\text { SDÜ, Mühendislik Fakültesi, } \\
\text { Karma (Uzaktan) Eğitim } \\
\text { Bilgisayar Mühendisliği }\end{array}$ & $\begin{array}{l}\text { Yüz yüze } \\
\text { Çoktan seçmeli }\end{array}$ & 50 \\
\hline & & $\begin{array}{l}\text { SDÜ, Uzaktan Eğitim Meslek } \\
\text { Yüksek Okulu, Bilgisayar } \\
\text { Programc1lığ }\end{array}$ & $\begin{array}{l}\text { Online } \\
\text { Çoktan Seçmeli }\end{array}$ & 68 \\
\hline
\end{tabular}




\section{B. METOT}

\section{B. 1. Bulanık Mantık Tabanlı Değerlendirme Algoritması}

Uzaktan eğitim sisteminin performansının değerlendirilmesi için bulanık mantık tabanlı değerlendirme algoritmas1 kullanılmaktadır. $\mathrm{Bu}$ değerlendirme dört parametre üzerinden yapılmaktadır. $\mathrm{Bu}$ parametreler; ses kalite parametresi (canlı dersler ve arşiv kayıtlarında), görüntü kalite parametresi (canlı dersler ve arşiv kayıtlarında), eğitim teknolojisi parametreleri (canlı derslerde).

Süleyman Demirel Üniversitesi Uzaktan Eğitim Meslek Yüksek Okulu bilgisayar programcıllğı ikinci sınıf öğrencilerinin katılımı ile uzaktan eğitim sistemi için öğrenci memnuniyet performansı ölçme çalışması yapılmıştır. Bu ölçüm çalışmasından elde edilen veriler geliştirilen bulanık mantık tabanlı değerlendirme modeli ile uzaktan eğitim sistemi için öğrenci memnuniyet performans değerlendirmesi hesaplanmıştır. Memnuniyet performansı hesaplanırken canlı derslerde yada arşiv derslerinde ki ses kalitesi, görüntü kalitesi ve eğitim teknolojileri (interakif) parametre olarak kullanılmıştır. Geliştirilen bulanık model üzerinde kullanılan algoritmadaki operatörler ve yöntemler aşağıda tablo2 de verilmiştir.

Tablo 2. Bulanık mantık tabanlı değerlendirme algoritmasının operatör ve yöntemleri

\begin{tabular}{ll}
\hline Operatör & Yöntem \\
\hline Bulanık “and” operatörü & $\min$ \\
\hline Bulanı “or" operatörü & $\max$ \\
\hline Uygulama Operatörü & $\min$ \\
\hline Birleştrme operatörü & sum \\
\hline Durulaştıma operatörü & mom \\
\hline
\end{tabular}

Algoritmanın tasarım ve uygulama çalışmalarında MATLAB Fuzzy Logic araç kutusu kullanılmıştır. Bulanık bir sistemin kurulumu ve analizi için aşağıdaki işlem basamakları sırasıyla uygulanmıştır. İşlem adımları;

a-) Girdi değişkenlerinin bulanıklaştırılması: bu işlem için sözel olarak tanımlanan değerlendirme ifadeleri üyelik fonksiyonları yardımıyla $[0,1]$ aralığında sayısal değerlere dönüştürülmüşlerdir. Algoritmanın tasarımında "zayıf" ve "mükemmel" durumlarını temsil etmek üzere iki farklı üyelik fonksiyonu oluşturulmuş ve bu fonksiyonlar üzerinden bulanıklaştırma işlemleri yapılmıştır. Kullanılan üyelik fonksiyonları ve tipleri aşağıda tablo 3 de verilmiştir. Kullanılan üyelik fonksiyonlarının karşılaştırmalı grafiği şekil 2'de verilmiştir. 


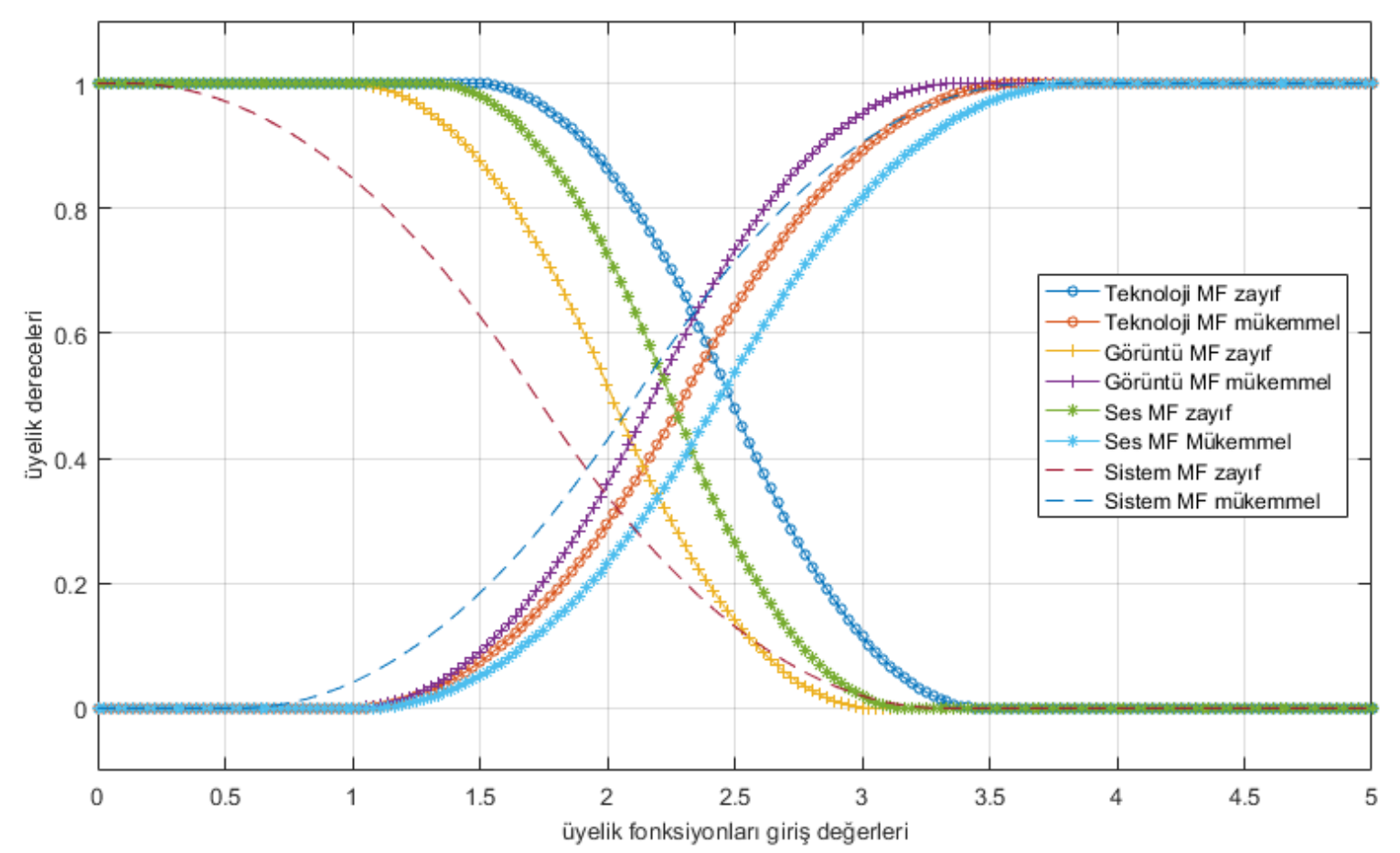

Şekil 2. Bulanık mantık tabanlı değerlendirme algoritmasının üyelik fonksiyonları $(M F)$ ve giriş-çıkış değerleri [17-20]

Tablo 3. Bulanık küme tabanlı değerlendirme algoritmasının üyelik fonksiyonları ve tipleri [19,20]

\begin{tabular}{|c|c|c|}
\hline Parametre & “zayıf” Üyelik Fonksiyonu & “mükemmel" Üyelik Fonksiyonu \\
\hline $\begin{array}{l}\text { Ses kalitesi, } \\
\text { Görüntü } \\
\text { kalitesi, Eğitim } \\
\text { Teknolojisi, } \\
\text { Sistem }\end{array}$ & $Z(x)=\left\{\begin{array}{c}1, x \leq a \\
1-2\left(\frac{x-a}{b-a}\right)^{2}, a \leq x \leq \frac{a+b}{2} \\
2\left(\frac{x-b}{b-a}\right)^{2}, \frac{a+b}{2} \leq x \leq b \\
0, x \geq b\end{array}\right.$ & $S(x)=\left\{\begin{array}{c}0, x \leq a \\
2\left(\frac{x-a}{b-a}\right)^{2}, a \leq x \leq \frac{a+b}{2} \\
1-2\left(\frac{x-b}{b-a}\right)^{2}, \frac{a+b}{2} \leq x \leq b \\
1, x \geq b\end{array}\right.$ \\
\hline
\end{tabular}

Bulanık küme tabanlı değerlendirme algoritmasında her bir giriş parametresi için "zayıf" ve "mükemmel" durumlarını temsil etmek için sırasıyla "Z" tipi ve "S" tipinde olmak üzere iki üyelik fonksiyonu kullanılmıştır [18-20]. Bu üyelik fonksiyonları uzman görüşleri kullanılarak tasarlanmış ve geliştirilmiş̧ir. Bundan dolayı sistem değerlendirme yaparken öncelik ve belirleyici katsayı ses kalitesi olarak belirlenmiştir.

b-) Kural tabanının oluşturulması; Bulanık çıkarım sistemi olarak "Mamdani" yöntemi kullanılmıştır. Mamdani yöntemi, üyelik fonksiyonlarını bulanık kümelere dönüştüren bir sistemdir. Mamdani sisteminde her kuralın çıktısı bulanık kümenin elemanıdır [16-18]. Mamdani sisteminde kural tabanı basit ve kullanışlıdır. $\mathrm{Bu}$ yüzden uzman görüşleri kullanılarak oluşturulan uzman-sistem uygulamalarında başarı oranı yüksektir. Sugeno çıkarım sistemi giriş parametrelerini doğrusal bir fonksiyona çevirdiğinden dolayı bu çalışmada tercih edilmemiştir.

Bulanık küme tabanlı değerlendirme algoritmasında sistemin giriş parametrelerine (ses kalitesi, görüntü kalitesi, eğitim teknolojisi) bağlı olarak "zayıf" yada "mükemmel” kararını vermesi için sekiz adet kural oluşturulmuştur. Bir önceki adımda olduğu gibi uzman görüşleri (öğretim elemanları) kullanılarak tasarlanmış ve geliştirilmiştir. Sistemin "mükemmel" üyelik fonksiyonuna çıkış yapabilmesi için ses ve görüntünün "mükemmel” olarak tanımlanan üyelik fonksiyonları üzerinden 
giriş alması gerekir. Aksi diğer tüm durumlarda "zayıf" üyelik fonksiyonu üzerinden çıkış yapılacaktır. Bulanık mantık tabanlı değerlendirme algoritmasının oluşturulan ve kullanılan kural tabanı aşağıda tablo 4'de verilmiştir.

Tablo 4. Bulanık küme tabanlı değerlendirme algoritmasının kural tabanı

\begin{tabular}{ll}
\hline $\mathbf{N o}$ & Kural \\
\hline $\mathbf{1}$ & $\begin{array}{l}\text { If (TEKNO is mükemmel) and (GÖRÜNTÜ is mükemmel) and (SES is mükemmel) } \\
\text { then (SISTTEM is mükemmel) (1) }\end{array}$ \\
\hline $\mathbf{2}$ & $\begin{array}{l}\text { If (TEKNO is zayıf) and (GÖRÜNTÜ is mükemmel) and (SES is mükemmel) then } \\
\text { (SİSTEM is mükemmel) (1) }\end{array}$ \\
\hline $\mathbf{3}$ & $\begin{array}{l}\text { If (TEKNO is mükemmel) and (GÖRÜNTÜ is zayıf) and (SES is mükemmel) then } \\
\text { (SISTTM is zayıf) (1) }\end{array}$ \\
\hline $\mathbf{4}$ & $\begin{array}{l}\text { If (TEKNO is zayıf) and (GÖRÜNTÜ is zayıf) and (SES is mükemmel) then } \\
\text { (SISSTEM is zayıf) (1) }\end{array}$ \\
\hline $\mathbf{5}$ & $\begin{array}{l}\text { If (TEKNO is mükemmel) and (GÖRÜNTÜ is mükemmel) and (SES is zayıf) then } \\
\text { (SİSTEM is zayıf) (1) }\end{array}$ \\
\hline $\mathbf{6}$ & $\begin{array}{l}\text { If (TEKNO is zayıf) and (GÖRÜNTÜ is mükemmel) and (SES is zayıf) then } \\
\text { (SISTEM is zayıf) (1) }\end{array}$ \\
\hline $\mathbf{7}$ & $\begin{array}{l}\text { If (TEKNO is mükemmel) and (GÖRÜNTÜ is zayıf) and (SES is zayıf) then } \\
\text { (SISSTEM is zayıf) (1) }\end{array}$ \\
\hline $\mathbf{8}$ & $\begin{array}{l}\text { If (TEKNO is zayıf) and (GÖRÜNTÜ is zayıf) and (SES is zayıf) then (SİSTEM is } \\
\text { zayıf) (1) }\end{array}$
\end{tabular}

c-) Bulanık operatörlerin uygulanması: bu aşamada iki farklı operatör çalışmaktadır. Birinci operatör (fuzzy operator) kural tabanındaki her bir kuralı oluşturan alt koşullar için giriş parametrelerinin üyelik fonksiyonlarından aldığı değerlerin tek bir bulanık kümeye dönüştürülmesidir. Bu çalışmada fuzzy operatör olarak "MIN" operatörü kullanılmıştır. İkinci operatör ise uygulama operatörüdür(apply implication operator). Birinci operatörden elde edilen bulanık kümenin değerinin kural tabanını oluşturan çıkış üyelik fonksiyonuna karşılık gelen değeridir. Sonuç olarak kural tabanındaki ilgili kuralın (koşullar bütünü) üretmiş olduğu bulanık küme değeridir. Çalışmamızda uygulama operatörü olarak "MIN" operatörü kullanılmıştır.

d-) sonuçların birleştirilmesi: her bir kuralın çıktılarını temsil eden bulanık kümelerin tek bir bulanık kümede birleştirilmedir. Toplama işleminin çıktısı da bir bulanık kümedir. Bu çalışmada birleştirme operatörü olarak "SUM" operatörü kullanılmıştır.

e-) durulaştırma: Durulaştırma işleminin girdisi, her bir kuralın çıktılarını temsil eden bulanık kümelerin birleşimidir. Durulaştırma işleminde girdi olarak kullanılan bulanık kümelerin birleşiminin maksimum olduğu noktaların ortalamasının alınması ile tek bir bulanık sayıya dönüştürülmesi işlemidir.

\section{ARASTIRMA BULGULARI}

Süleyman Demirel Üniversitesi Uzaktan Eğitim Meslek Yüksek Okulu bilgisayar programc1llğı ikinci sınıf öğrencilerinin katılımı ile uzaktan eğitim sistemi için değerlendirme çalışması yapılmıştır. Çalışmada öğrencilerimize uzaktan eğitim (canlı yada arşiv) derslerindeki ses kalitesi, görüntü kalitesi ve eğitim teknolojileri (etkileşim) ile ilgili üç soru yöneltilmiştir. Bu sorular ve verilen cevaplar aşağıda tablo 5'de verilmiştir. 
Tablo 5. Uzaktan eğitim sistemi öğrenci memnuniyet performans anketi istatistikleri

\begin{tabular}{|c|c|c|c|c|c|c|c|}
\hline Soru & $\begin{array}{l}\text { Çok } \\
\text { Kötü }\end{array}$ & Kötü & Orta & İyi & $\begin{array}{l}\text { Çok } \\
\text { İyi }\end{array}$ & Toplam & \\
\hline \multirow{2}{*}{$\begin{array}{l}\text { Canli derslerde ve } \\
\text { arşiv derslerinde ses } \\
\text { kalitesi yeterli mi? }\end{array}$} & 1 & 3 & 12 & 35 & 17 & 68 & Frekans \\
\hline & $\% 1,5$ & $\% 4,4$ & $\% 17,6$ & $\% 51,5$ & $\% 25,0$ & $\% 100$ & Yüzde \\
\hline \multirow{2}{*}{$\begin{array}{l}\text { Canlı derslerde ve } \\
\text { arşiv derslerinde } \\
\text { görüntü(Ekran } \\
\text { Paylaşımı / Kamera ) } \\
\text { kalitesi yeterli mi? }\end{array}$} & 1 & 3 & 14 & 33 & 17 & 68 & Frekans \\
\hline & $\% 1,5$ & $\% 4,4$ & $\% 20,6$ & $\% 48,5$ & $\% 25,0$ & $\% 100$ & Yüzde \\
\hline \multirow[b]{2}{*}{$\begin{array}{l}\text { Canlı derslerde ve } \\
\text { arşiv derslerinde } \\
\text { interaktif } \\
\text { (etkileşimli) eğitim } \\
\text { için eğitim } \\
\text { teknolojileri / } \\
\text { donanımları yeterli } \\
\text { mi? }\end{array}$} & 0 & 4 & 15 & 29 & 20 & 68 & Frekans \\
\hline & 0 & $\% 5,9$ & $\% 22,1$ & $\% 42,6$ & $\% 29,4$ & $\% 100$ & Yüzde \\
\hline
\end{tabular}

$\mathrm{Bu}$ çalışmadan elde edilen veriler geliştirilen bulanık mantık tabanlı değerlendirme algoritması ile uzaktan eğitim sistemi için öğrenci memnuniyet performansı hesaplanmıştır. Uzaktan eğitim sistemi için öğrenci memnuniyet performansı hesaplanırken canlı derslerde yada arşiv derslerinde ki ses kalitesi, görüntü kalitesi ve eğitim teknolojileri (etkileşim) parametre olarak kullanılmıştır. Sistem değerlendirmesi yapılırken kullanılan en önemli parametre ses ve görüntüdür. Sistem tasarımı yapılırken (üyelik fonksiyonu tasarlanırken ve kural tabanı oluşturulurken) bu iki parametre özellikle ses parametresi belirleyici olmuştur. Uzaktan eğitim sistemi için öğrenci memnuniyet performansına ses ve görüntü parametrelerinin etkisi aşağıda şekil 3'de verilmiştir.

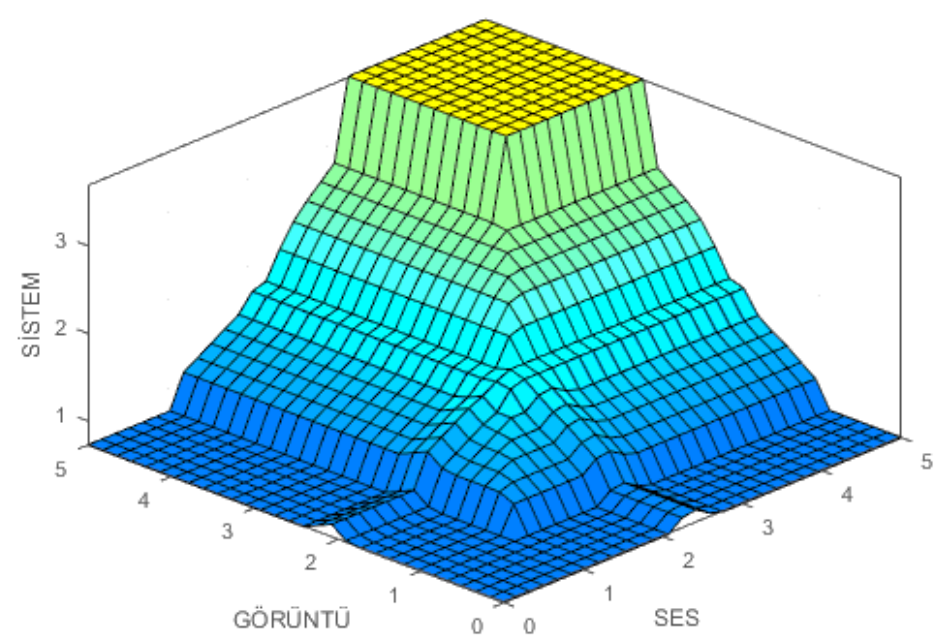

Şekil 3. Bulanık mantık tabanlı değerlendirme algoritmasında ses ve görüntü üyelik fonksiyonlarının uzaktan eğitim sistemi için öğrenci memnuniyet performansına etkisi

Geliştirilen bulanık model üzerinde bazı giriş değerlerine ait hesaplama sonuçları aşağıda tablo 6'da verilmiştir. Ayrıca bu değerler için merkezi eğilim ölçüleri tabloda sunulmuştur. Tasarlanan bulanık mantık tabanlı değerlendirme algoritması ile merkezi eğilim ölçülerinin birbirlerine yaklaşımları tablo 6'da karşılaştırmalı olarak verilmiştir. 
Tablo 6. Bulanık mantık tabanlı değerlendirme algoritmasının bazı giriş değerleri için hesaplanan sonuçları ve merkezi ĕ̆ilim ölçümleri (uzaktan eğitim sistemi için öğrenci memnuniyet performansı)

\begin{tabular}{lllllllll}
\hline $\begin{array}{l}\text { Eğitim } \\
\text { Teknolojisi }\end{array}$ & $\begin{array}{l}\text { Görüntü } \\
\text { kalitesi }\end{array}$ & $\begin{array}{l}\text { Ses } \\
\text { kalitesi }\end{array}$ & $\begin{array}{l}\text { Sistem } \\
\text { Başarısı } \\
(\boldsymbol{F u z z y})\end{array}$ & $\begin{array}{l}\text { Aritmetik } \\
\text { Ortalama }\end{array}$ & $\begin{array}{l}\text { Geometrik } \\
\text { Ortalama }\end{array}$ & $\begin{array}{l}\text { Harmonik } \\
\text { Ortalama }\end{array}$ & $\begin{array}{l}\text { Ağırlıklı } \\
\text { Ortalama }\end{array}$ & $\begin{array}{l}\text { Kareli } \\
\text { Ortalama }\end{array}$ \\
\hline $\mathbf{4}$ & 4 & 4 & $\mathbf{4 , 3 5}$ & 4,0 & 4,0 & 4,0 & 4 & 4 \\
\hline $\mathbf{4}$ & 4 & 3 & $\mathbf{2 , 8 8}$ & 3,7 & 3,6 & 3,6 & 3,5 & 3,7 \\
\hline $\mathbf{4}$ & 3 & 4 & $\mathbf{3 , 2}$ & 3,7 & 3,6 & 3,6 & 3,7 & 3,7 \\
\hline $\mathbf{3}$ & 4 & 4 & $\mathbf{4}$ & 3,7 & 3,6 & 3,6 & 3,8 & 3,7 \\
\hline $\mathbf{3}$ & 3 & 3 & $\mathbf{2 , 8 8}$ & 3,0 & 3,0 & 3,0 & 3 & 3 \\
\hline $\mathbf{3}$ & 3 & 2 & $\mathbf{1 , 3}$ & 2,7 & 2,6 & 2,6 & 2,5 & 2,7 \\
\hline $\mathbf{3}$ & 2 & 3 & $\mathbf{1 , 7}$ & 2,7 & 2,6 & 2,6 & 2,7 & 2,7 \\
\hline $\mathbf{2}$ & 3 & 3 & $\mathbf{2 , 8 8}$ & 2,7 & 2,6 & 2,6 & 2,8 & 2,7 \\
\hline $\mathbf{2}$ & 2 & 2 & $\mathbf{1 , 6 5}$ & 2,0 & 2,0 & 2,0 & 2 & 2 \\
\hline $\mathbf{1}$ & 1 & 1 & $\mathbf{0 , 0 5}$ & 1,0 & 1,0 & 1,0 & 1 & 1 \\
\hline
\end{tabular}

Yapılan hesaplamalarda uzaktan eğitim sistemi için öğrenci memnuniyet performans değerlendirmesi ile öğrencilere ait genel not ortalaması verileri eşleştirilmiştir. Eşleştirme sonucunda verilerin düzensiz dağ 1 lım gösterdiği şekil 4'de gözlenmiştir. Veriler arasında korelasyon 0.17 olarak hesaplanmıștır. Buradan da öğrencilerimizin uzaktan eğitim sistemlerinden beklentilerinin heterojen dağılım gösterdiği görülmektedir. Ayrıca verileri MatLab uygulamasını kullanarak matematiksel model tasarlanmak istediğimizde dokuzuncu dereceden polinom regresyon modeli için R-square $=0.4687$, ikinci olarak kullanılan lineer interpolasyon modelinde R-square=1 olarak hesaplanmıştır. Buradan da düzensiz dağ 1 lım gösteren verilerde interpolasyon işlemlerinin regresyon işlemlerine göre daha iyi sonuç verdiği gözlemlenmiştir.

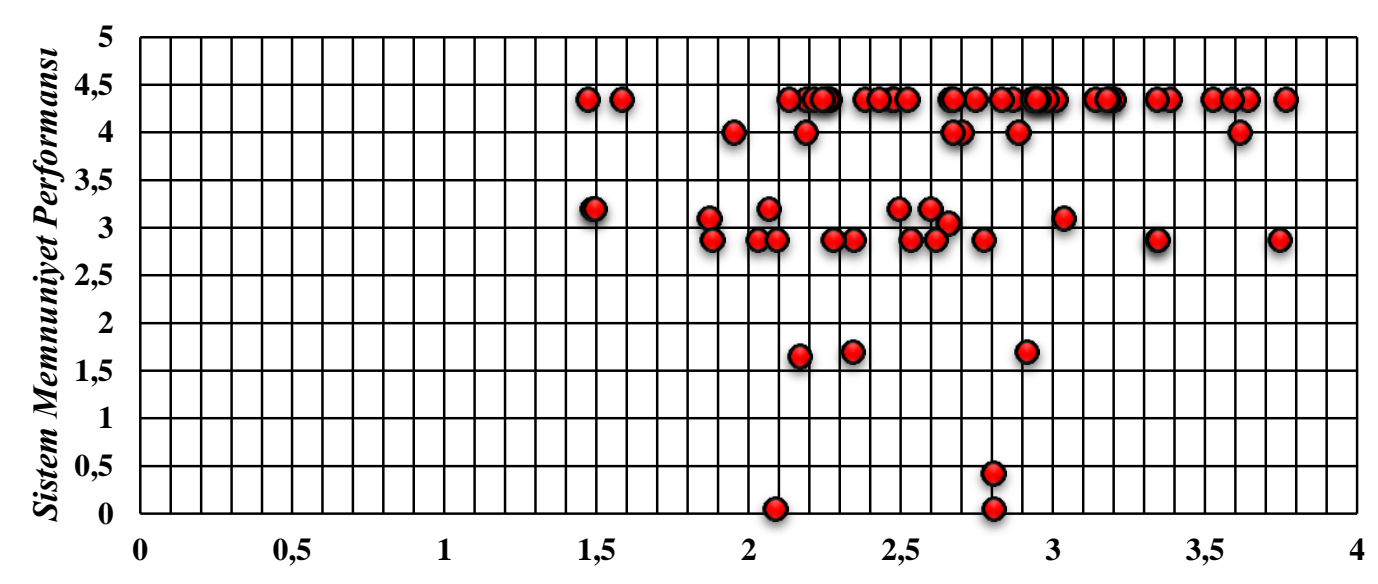

Öğrenci Genel Not Ortalamast

Şekil 4. Uzaktan eğitim sistemi için öğrenci memnuniyet performans değeri ile öğrenci genel not ortalaması dă̆gllm grafiği

\section{SONUC}

Süleyman Demirel Üniversitesi Uzaktan Eğitim Meslek Yüksek Okulu bilgisayar programc1llğı ikinci sınıf öğrencilerinin katılımı ile uzaktan eğitim sistemi için öğrenci memnuniyet performansı ölçme çalışması yapılmıştır. Çalışmada öğrencilerimize uzaktan eğitim (canlı yada arşiv) derslerindeki ses kalitesi, görüntü kalitesi ve eğitim teknolojileri (etkileşim) ile ilgili üç soru yöneltilmiştir. $\mathrm{Bu}$ 
çalışmadan elde edilen veriler kullanılarak geliştirilen bulanık mantık tabanlı değerlendirme algoritması ile uzaktan eğitim sistemi için öğrenci memnuniyet performansı hesaplanmıştır. Uzaktan eğitim sistemi için öğrenci memnuniyet performansı hesaplanırken canlı derslerde yada arşiv derslerinde ki ses kalitesi, görüntü kalitesi ve eğitim teknolojileri (etkileşim) parametre olarak kullanılmıştır. Sistem tasarımı yapılırken uzman görüşleri kullanılarak parametre ağırlıkları tespit edilmiştir. Sistem değerlendirmesi yapılırken kullanılan en önemli parametre ses ve görüntüdür. Üyelik fonksiyonu tasarlanırken ve kural tabanı oluşturulurken bu iki parametre özellikle ses parametresi belirleyici olmuştur. Bulanık tabanlı değerlendirme algoritmasının tasarımı ve uygulama çalışmalılarında elde edilen sonuçlar aşağıda verilmiştir.

- Bulanık küme tabanlı değerlendirme algoritmasında giriş ve çıkış parametreleri, üyelik fonksiyonları, kural tabanı ve bulanık operatörler uzman görüşleri(öğretim elemanları) kullanılarak tasarlanmış ve geliştirilmiştir. $\mathrm{Bu}$ tip algoritmalar uzman görüşlerine göre sonuçlar üretmektedir. $\mathrm{Bu}$ çalışmada üretilen sonuçlar uzman görüşlerini yansıttı̆̆ için uzman-sistem olarak sadece ilgili problemin ilgili uzman görüşüne göre analizi için kullanımı doğru sonuçlar verecektir.

- Bir sistemin performans durumu değerlendirilirken "kötü", "orta", "iyi" gibi derecesi ve niteliği; sistemi değerlendiren kişiye veya bulunduğu ortamın kendine özgü koşullarına göre farklılıklar göstermektedir.

- Bulanık tabanlı değerlendirme algoritmalarında hesaplamalar üyelik fonksiyonları, kural tabanı ve bulanık operatörlerin dahil olduğu bir süreçte hesaplanır. $\mathrm{Bu}$ tip performans değerlendirmeleri istatiksel olarak merkezi eğilim ölçüleri ile hesaplanması durumunda beklenen (uzman-sistem) değerleri sağlamadığı görülmüştür.

- Yapılan hesaplamalarda uzaktan eğitim sistemi için öğrenci memnuniyet performans değerlendirmesi ile öğrencilere ait genel not ortalaması verileri eşleştirilmiştir. Verilerin düzensiz dağılım gösterdiği gözlenmiştir. Veriler arasında korelasyon 0.17 olarak hesaplanmıştır. Buradan da öğrencilerimizin bölüm derslerindeki alt yapı hazır bulunuşlukları, uzaktan eğitim sistemlerinden beklentileri, kişisel farklılıkları (yaş, meslek, gelir, ...) heterojen dağılım gösterdiği görülmektedir. Ayrıca bu verilere ait MatLab uygulaması üzerinde bir matematiksel model tasarlanmak istediğimizde dokuzuncu dereceden polinom regresyon modeli için $\mathrm{R}$-square $=0.4687$, ikinci olarak kullanılan lineer interpolasyon modelinde r-square $=1$ olarak hesaplanmıştır. Düzensiz dağılım gösteren verilerde interpolasyon işlemlerinin regresyon işlemlerine göre daha iyi sonuç verdiği gözlemlenmiştir.

- Aynı uzaktan eğitim alt yapısını kullanan SDÜ Mühendislik Fakültesi, Karma (Uzaktan) Eğitim Bilgisayar Mühendisliği programlarındaki öğrencilerimizin, SDÜ Uzaktan Eğitim Meslek Yüksek Okulu Bilgisayar Programcılığı programındaki öğrencilerimize göre sistem beklentilerinin daha yüksek olduğu gözlemlenmiştir. SDÜ Uzaktan Eğitim Meslek Yüksek Okulu Bilgisayar Programcılığı öğrencilerimizin, Uzaktan eğitim sistemi için öğrenci memnuniyet performans değerlendirmelerinin [2.75,3.25] aralığında(orta) ve $[4,5]$ aralığında (iyi-çok iyi) eğilim-yığılma gösterdiği gözlemlenmiştir.

\section{KAYNAKLAR}

[1] Y. Shi, W. Xie, G. Xu, R. Shi, E. Chen, Y. Mao, and F. Liu, "The smart classroom: merging technologies for seamless tele-education," IEEE Pervasive Computing, vol. 2, no. 2, pp. 47-55, 2003.

[2] L. R. Winer and J. Cooperstock, "The 'Intelligent Classroom': Changing teaching and learning with an evolving technological environment," Computers \& Education, vol. 38, no. 1-3, pp. 253-266, 2002. 
[3] Y. Shi, W. Xie and G. Xu, "Smart remote classroom: creating a revolutionary real-time interactive distance learning system," Advances in Web-Based Learning. ICWL 2002. Lecture Notes in Computer Science, J. Fong, C.T. Cheung, H.V. Leong, Q. Li Q, Eds. Berlin: Springer, 2002, pp. 130141.

[4] H. Ren and G. Xu, "Human action recognition in smart classroom," Proceedings of Fifth IEEE International Conference on Automatic Face Gesture Recognition, 2002, pp. 417-422.

[5] Z. Wang, "Smart spaces: creating new instructional space with smart classroom technology," New Library World, vol. 109, no. 3/4, pp. 150-165, 2008.

[6] B. Carter and T. Linder, "Collaborative learning environments: developing smart classrooms in theory and in practice," Advances in Educational Administration, vol. 8, pp. 201-211, 2006.

[7] T. Tibúrcio and E. Finch, "The impact of an intelligent classroom on pupils' interactive behaviour," Facilities, vol. 23, no. 5/6, pp. 262-278, 2005.

[8] S. Y. Stephen, S. K. S. F Karim, S. I. Ahmed, Y. Wang and B. Wang, "Smart classroom: Enhancing collaborative learning using pervasive computing technology," In ASEE Annual Conference Proceedings, 2003, pp. 13633-13642

[9] G. Bautista and F. Borges, "Smart Classrooms: Innovation in formal learning spaces to transform learning experiences," Bulletin of the IEEE Technical Committee on Learning Technology, vol. 15, no. 3, pp. 18-21, 2013.

[10] H. Ren and G. Xu, "Human action recognition in smart classroom," Proceedings of Fifth IEEE International Conference on Automatic Face Gesture Recognition, 2002, pp. 399-404.

[11] N. Baykal ve T. Beyan, 2004. Bulanık Mantık Illke ve Temelleri, Ankara, Türkiye: Biçaklar Kitabevi, 2004, böl. 11, ss. 335-387.

[12] N. Baykal ve T. Beyan, Bulanık Mantık Uzman Sistemler ve Denetleyiciler, Ankara, Türkiye: Bıçaklar Kitabevi, 2004, böl. 2,3,4, ss. 99-154, 155-264, 265-326.

[13] L. A., Zadeh, "Information and control," Fuzzy Sets, vol. 8, no. 3, pp. 338-353, 1965.

[14] ～L. A., Zadeh. "Fuzzy Logic," Computer, vol. 21, no. 4, pp. 83-93, 1988.

[15] D. Dubois, and H.M. Prade, Fuzzy Sets and Systems: Theory and Applications, Mathematics in Science and Engineering, v. 144. New York: Academic Press, 1980, pp. 9-34.

[16] E.H., Mamdani and S., Assilian, "An experiment in linguistic synthesis with a fuzzy logic controller," International Journal of Man-Machine Studies, vol. 7, no. 1, pp. 1-13, 1975.

[17] MathWorks Inc. (2021, October 24). Mamdani and Sugeno Fuzzy Inference Systems [Online]. Available: https://www.mathworks.com/help/fuzzy/types-of-fuzzy-inference-systems.html.

[18] MathWorks Inc. (2021, October 24). Foundations of Fuzzy Logic [Online]. Available: https://www.mathworks.com/help/fuzzy/types-of-fuzzy-inference-systems.html.

[19] MathWorks Inc. (2021, October 24). Z-shaped membership function [Online]. Available: https://www.mathworks.com/help/fuzzy/zmf.html. 
[20] MathWorks Inc. (2021, October 24). S-shaped membership function [Online]. Available: https://www.mathworks.com/help/fuzzy/smf.html. 